www.jmscr.igmpublication.org

Impact Factor 5.84

Index Copernicus Value: 83.27

ISSN (e)-2347-176x ISSN (p) 2455-0450

crossref DOI: https://dx.doi.org/10.18535/jmscr/v5i8.87

\title{
Original Article \\ Efficacy of Ichthammol Glycerin Pack and Steroid Antibiotic Pack as Initial Treatment of Acute Otitis Externa: A Comparative Study
}

\author{
Jasdeep Monga ${ }^{1}$, Shweta Sharma ${ }^{2}$, Preeti Singh ${ }^{3}$, Vishal Pathania ${ }^{4}$ \\ ${ }_{1,3}^{1,3}$ Assistant Professor, ${ }^{2}$ Senior Resident, ${ }^{4}$ Associate Professor \\ SGT Medical College, Budhera, Gurugram
}

\begin{abstract}
Introduction: Otitis externa, characterized by general oedema and erythema of the external auditory canal, can be treated by various modalities including aural toilet, topical antibiotic agents, with or without corticosteroids. This prospective randomized study has been undertaken to compare the efficacy of ichthammol glycerin pack with steroid antibiotic pack as the initial treatment for acute otitis externa.

Materials and Methods: A prospective randomized study was carried out on 60 patients diagnosed with acute otitis externa. The patients were randomly divided into two groups. In group A, Ichthammol glycerin pack was kept and in group B, steroid antibiotic pack was inserted. In all the patients the tragal tenderness, VAS score and edema score at the time of presentation were compared with these scores at two days follow up.

Results: It was observed that there was statistically significant decrease in the mean pain score and the edema of the external auditory canal $(p<0.001)$ in both group A as well as group B. Even the tragal tenderness significantly improved within $48 \mathrm{hrs}$. in both groups $(p<0.001)$. But there was no statistically significant difference in the efficacy of both the groups compared to each other.

Conclusion: In this study, both ichthammol glycerin as well as antibiotic steroid combination proved to be effective as the initial treatment of acute otitis externa. Still we would like to recommend ichthammol glycerin pack as initial treatment as it is more cost effective with no risk of antibiotic resistance and is safe in cases of immunocompromised patients.
\end{abstract}

\section{Introduction}

Otitis externa is defined as a generalized condition of the external auditory canal that is characterized by general oedema and erythema associated with itchy discomfort ${ }^{[1]}$. It is estimated to have a prevalence of 0.4 percent per year, affecting 10 percent of the population during their life time ${ }^{[2]}$. The bacteriology of otitis externa has not changed significantly over the last few decades. The most common organism being involved is Pseudomonas followed by other gram-negative organisms, staphylococcus aureus and streptococci ${ }^{[3]}$. Acute otitis externa is more common in regions with warmer climates, increased humidity or increased water exposure from swimming ${ }^{[4,5]}$. The diagnosis of acute otitis externa is mainly clinical and is based on the symptoms and signs like pain, itching, oedema and erythema of the external auditory canal with purulent otorrhea and debris in the meatus ${ }^{[6]}$. The treatment of acute otitis externa includes aural toilet, topical antibiotic agents, with or without corticosteroids and less commonly systemic antibiotics $^{[7]}$. The most common topical treatment being used is glycerol and ichthammol combination. It has proven dehydrating and anti- 
inflammatory properties and antibacterial activity against streptococci and staphylococci, but poor activity against pseudomonas ${ }^{[8,9]}$. Studies have shown the use of topical antibiotics ${ }^{[10]}$, topical steroid $^{[11,12]}$, or a combination of topical antibiotic and steroid ${ }^{[13]}$ as the initial treatment of otitis externa. But very few studies have directly compared the use of glycerol and ichthammol combination with other forms of topical medications ${ }^{[14,15,16]}$. This prospective randomized study has been undertaken to compare the efficacy of ichthammol glycerin pack with steroid antibiotic pack as the initial treatment for acute otitis externa.

\section{Materials and Methods}

A prospective randomized study was carried out on 60 patients at Department of ENT, SGT Medical College, Gurgaon. Patients of more than 18 years of age presenting in our outpatient department from November 2014 to December 2016 and diagnosed to have acute otitis externa were included in the study. In few patients with bilateral involvement only one ear on random basis was included and the other ear was excluded from the study. The diabetic \& immunocompromised patients were excluded. Even the patients with concurrent middle ear disease were excluded from the study. In all the patients, proper aural toileting under microscope was done before putting the ear pack. The patients were randomly divided into two groups. In group A, Ichthammol glycerin pack was kept and in group B, steroid antibiotic pack was inserted. For steroid antibiotic group, we used sofradex cream, which is a combination of framycetin sulphate $(1 \%)$ and dexamethasone acetate $(0.1 \%)$.

In all the patients, after clinical examination once the diagnosis of otitis externa was being made, the assessment of the pain due to otitis externa was done by using Visual analogue scale (VAS). For calculating the VAS score, ten images of facial expression showing the grade of pain and discomfort were used $\&$ each image was given a score of one point. After evaluating the VAS score, microscopy was being done to clear any discharge or debris from external auditory canal and assessment of the canal skin and oedema was done. The severity of oedema was evaluated, based on the ability of visualization of the tympanic membrane. Depending on whether the tympanic membrane is completely visible, partly visible or not visible at all due to oedema, the cases were divided into mild, moderate and severe oedema and given scores of 1, 2 and 3 respectively. After this initial proper assessment, ear packing was done either by ichthammol glycerin pack or sofradex pack. Along with that all patients were prescribed amoxycillin with clavulanic acid orally. All the patients were called for follow up after 2 days for reassessment of the tragal tenderness, VAS score as well as the oedema score. These scores at first follow up were compared with the one at presentation. Proper statistical analysis was done using different tests for comparison of the scores within and between the two groups.

\section{Results}

A total of 60 patients were involved in the study. The mean patient age was 36 years. Out of which 35 were males and 25 were females. The right ear was involved in 39 cases and the left in 21 cases. All the patients were randomly divided into two groups with 30 patients in each group. In Group A, patients received ichthammol glycerin pack, while in group B, sofradex pack was kept in the external auditory canal. The effectiveness of the treatment in each group was qualitatively assessed by improvement in tragal tenderness. Out of all the 60 patients who presented with significant tragal tenderness, at first follow up 26 patients in group A and 25 patients in group B had very mild or no tragal tenderness at all which was statistically significant $(\mathrm{p}<0.001)$ improvement. The comparison of mean VAS score was done at presentation and at first follow-up using the paired t-test. The mean VAS score decreased significantly from presentation to first follow-up in both group A as well as group B (Table 1\&2). 
Table 1- VAS score in group A before and after treatment

\begin{tabular}{|l|c|c|c|c|c|}
\hline & \multicolumn{5}{|c|}{ GROUP A } \\
\hline VAS score & Mean & Std. Deviation & $\begin{array}{c}\text { Mean } \\
\text { difference }\end{array}$ & t-test value & p-value \\
\hline At presentation & 5.70 & 0.92 & 2.63 & 21.570 & $<0.001^{*}$ \\
\hline At first follow up & 3.07 & 1.143 & & & \\
\hline
\end{tabular}

Table 2- VAS score in group B before and after treatment

\begin{tabular}{|l|c|c|c|c|c|}
\hline & \multicolumn{5}{|c|}{ GROUP B } \\
\hline VAS score & Mean & $\begin{array}{c}\text { Std. } \\
\text { Deviation }\end{array}$ & $\begin{array}{c}\text { Mean } \\
\text { difference }\end{array}$ & t-test value & -value \\
\hline At presentation & 6.03 & 0.72 & 3.27 & 20.605 & $<0.001^{*}$ \\
\hline At first follow up & 2.77 & 0.90 & & & \\
\hline
\end{tabular}

The comparison of mean VAS score at presentation and at first follow up was done between groups $\mathrm{A}$ and $\mathrm{B}$ using the unpaired t-test.
There was no significant difference in mean VAS score at presentation and at first follow up between groups A and B (Fig 1)

Fig 1- Comparison of VAS scores within and between groups



The comparison of mean edema score was done at presentation and at first follow-up using the Wilcoxon signed rank test. The mean edema score decreased significantly from presentation to first follow-up in both the groups (Table $3 \& 4$ )

Table 3- Edema score in group A before and after treatment

\begin{tabular}{|l|c|c|c|c|c|}
\hline & \multicolumn{5}{|c|}{ GROUP A } \\
\hline Edema score & Mean & $\begin{array}{c}\text { Std. } \\
\text { Deviation }\end{array}$ & $\begin{array}{c}\text { Mean } \\
\text { difference }\end{array}$ & t-test value & p-value \\
\hline At presentation & 2.07 & 0.52 & 0.80 & 9.049 & $<0.001^{*}$ \\
\hline At first follow up & 1.27 & 0.45 & & & \\
\hline
\end{tabular}

Table 4- Edema score in group B before and after treatment

\begin{tabular}{|l|c|c|c|c|c|}
\hline & \multicolumn{5}{|c|}{ GROUP B } \\
\hline Edema score & Mean & Std. Deviation & $\begin{array}{c}\text { Mean } \\
\text { difference }\end{array}$ & t-test value & p-value \\
\hline At presentation & 2.30 & 0.53 & 1.20 & 13.573 & $<0.001^{*}$ \\
\hline At first follow up & 1.10 & 0.31 & & & \\
\hline
\end{tabular}


The comparison of mean Edema score at presentation and at first follow up was done between groups A and B using the Mann-whitney
$\mathrm{U}$ test. There was no significant difference in mean Edema score at presentation and at first follow up between groups A \& B (Fig 2).

Fig 2- Comparison of edema score within and between the groups

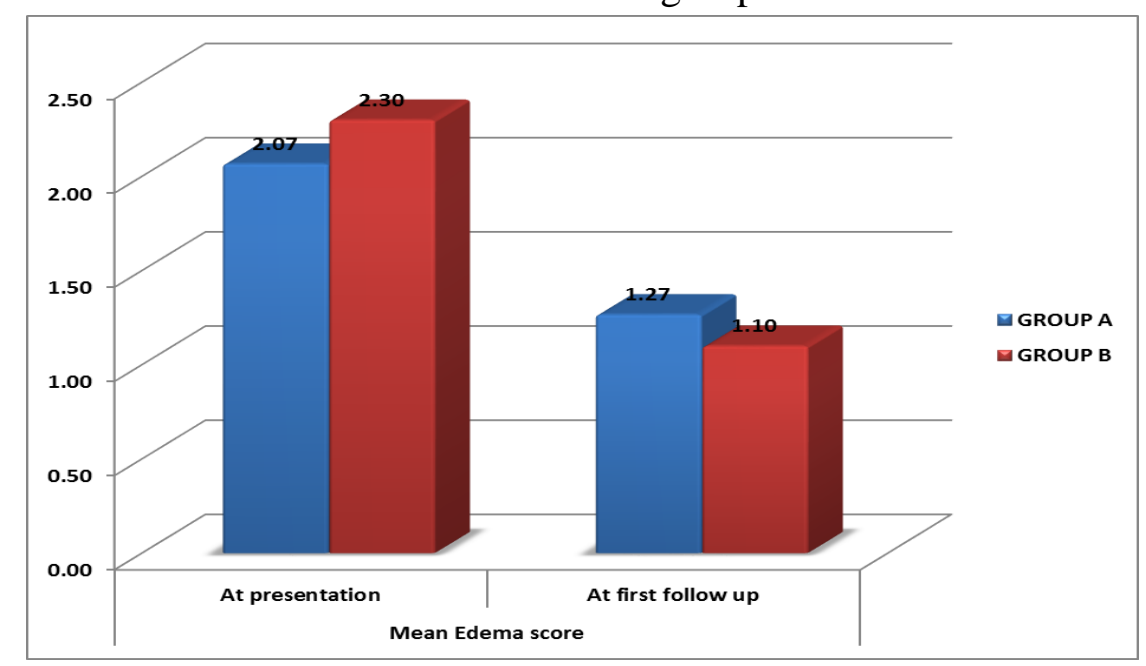

\section{Discussion}

Acute otitis externa is a diffuse inflammation of the external ear canal. A diagnosis of diffuse acute otitis externa requires rapid onset, generally within 48 hours, in the past 3 weeks of symptoms and signs of ear canal inflammation. A sign of diffuse acute otitis externa is tenderness of the tragus. Also known as "swimmer's ear" or "tropical ear," acute otitis externa is one of the most common infections encountered by clinicians ${ }^{[1,7]}$. Usually, treatment of external otitis is topical drug therapy, rather than oral antibiotics or surgery, as the disease is limited to the skin of the ear canal ${ }^{[17]}$. The local treatment includes aural toilet, topical antibiotic agents, with or without corticosteroids and less commonly systemic antibiotics ${ }^{[7]}$. The most common topical treatment being used is glycerol and ichthammol combination. It has proven dehydrating and antiinflammatory properties and antibacterial activity against streptococci and staphylococci, but poor activity against pseudomonas ${ }^{[8,9]}$. The treatment of acute otitis externa with local wicks, gauze or drops containing corticosteroids combined with a broad-spectrum antibiotic is also being shown in many studies. The use of an ointment instead of drops in the treatment of otitis externa has both pros and cons. According to some studies the occlusive effect of an ointment may raise the humidity in the affected ear ${ }^{[18]}$. While the factor in favor of ointment is that the hypersensitivity reactions are comparatively less as compared to the drops. In cases of tympanic membrane perforation also ointment is better as drugs present in ear drops are potentially ototoxic ${ }^{[19]}$.

Hornigold et al, compared the use of glycerol and icthammol (G\&I) ribbon gauze with the topical antibiotic and steroid drops in the management of otitis externa. A total of 43 patients were involved with 48 infected ears. In the randomized trial of G\&I ribbon gauze versus topical antibiotic drops, there was no significant difference in terms of pain relief, canal wall oedema, or aural discharge [15].

Masood et al., in a prospective single-blind randomized controlled trial compared the efficacy of $10 \%$ glycerine-ichthammol (GI) solution and Triadcortyl ${ }^{\circledR}$ (TAC) ointment as local dressing in the management of severe acute otitis externa. A total of 64 patients were studied. It was shown that both the treatments were effective in the treatment of severe acute otitis externa. Although there was a statistically significant improvement of pain parameters in the TAC group, they found no significant differences in clinical findings between the two groups. Therefore, it was recommended 
by them that GI dressing can be used instead of an antibiotic dressing as an initial treatment of severe acute otitis externa based on cost, avoidance of resistance and toxicity ${ }^{[16]}$. The results of our study were almost like this study as in our study there was no statistically significant difference between the efficacy of ichthammol glycerin group and sofradex group.

The clinical trial by Bhatta et al showed different results as compared to our study. They compared the clinical efficacy of $10 \%$ Ichthammol-glycerin pack with steroid-antibiotic pack in relieving pain in cases of acute otitis externa in a prospective randomized clinical trial on 106 patients. They showed statistical significant decrease in number of visits in steroid group $(\mathrm{p}<0.05)$ and concluded that Steroid-antibiotic pack can be used for earlier relief of pain and decrease number of visits in management of acute otitis externa ${ }^{[20]}$.

In our study, the mean age of presentation came out to be 36 years, which is a middle age group. The middle age being the most common involvement is same as observed by Hornigold et al ${ }^{[15]}$ but in contrast to some other studies, like Bhatta et al ${ }^{[20]}$ observed mean age as 20.8 years while Neher et $\mathrm{al}^{[21]}$ showed comparatively older age group being involved as compared to our study. We observed slight male preponderance with total 35 males and 25 females. This is almost same as observed by Masood et al ${ }^{[16]}$. The right ear involvement was more as compared to left one which was also observed in other studies like Bhatta et $\mathrm{al}^{[20]}$. This result might be because of comparatively more people with right handedness among the population and thus more chances of self-inflicted injury.

In our study, we did not focus on the overall efficacy but the comparison of the efficacy of both the modalities as the initial treatment. As, later we can receive antibiotic sensitivity tests also and accordingly we can prescribe antibiotics for even better control. But at the time of presentation of the patient, a good initial treatment is must for better relief of the symptoms and overall improvement in the disease process. We observed that there was statistically significant decrease in the mean pain score and the edema of the external auditory canal $(p<0.001)$ in both Ichthammol glycerin group (group A) as well as steroid antibiotic group (group B). Even the tragal tenderness significantly improved within $48 \mathrm{hrs}$. in both groups $(\mathrm{p}<0.001)$. But there was no statistically significant difference in the efficacy of both the groups compared to each other. Although, as discussed already, other similar study by Bhatta et al ${ }^{[20]}$ and by Shrestha et al ${ }^{[14]}$ have shown that steroid-antibiotic pack is better for earlier relief of pain leading to decrease number of hospital visits in the management of acute otitis externa.

\section{Conclusion}

In this study, both ichthammol glycerin as well as antibiotic steroid combination proved to be effective as the initial treatment of acute otitis externa with no adverse effects being observed. Still we would like to recommend ichthammol glycerin pack as initial treatment as it is more cost effective with no risk of antibiotic resistance and is safe in cases of immunocompromised patients.

\section{References}

1. Carney AS. Otitis externa and otomycosis. In: Gleeson M(ed.), Scott Brown's Otorhinolaryngoly: Head and Neck Surgery, Vol 3, $7^{\text {th }}$ edition, Hodder Arnold: London. 2008 p. 3351.

2. Bojrab DI, Bruderly T, Abdulrazzak Y. Otitis externa. Otolaryngol Clin North Am 1996;29:761-82.

3. Carney AS. Otitis externa and otomycosis. In: Gleeson M(ed.), Scott Brown's Otorhinolaryngoly: Head and Neck Surgery, Vol 3, $7^{\text {th }}$ edition, Hodder Arnold: London. 2008 p. 3352.

4. Russell JD, Donnelly M, McShane DP, et al. What causes acute otitis externa? J Laryngol Otol 1993;107:898-901.

5. Hajjartabar M. Poor-quality water in swimming pools associated with a 
substantial risk of otitis externa due to Pseudomonas aeruginosa. Water Sci Technol 2004;50:63-7.

6. Holten KB, Gick J. Management of the patient with otitis externa. Journal of Family Practice. 2001;50:353-60.

7. Rosenfeld RM et al. Clinical practice guideline: acute otitis externa. Otolaryngol Head Neck Surg 2006;134:S4-23.

8. Ahmed k, Roberts ML, Manninon PT. Antimicrobial activity of glycerineichthamol in otitis externa. Clin Otolaryngol Allied Sci 1995;20:201-3.

9. Nilssen E, Wormald PJ, Oliver S. Glycerol and ichthammol: medicinal solution or mythical potion? J Laryngol Otol. 1996;110:319-21.

10. Rosenfeld RM, Singer M, Wasserman JM, et al. System review of topical antimicrobial therapy for acute otitis externa. Otolaryngol Head Neck Surg. 2006;134:S24-48.

11. Jacobsson S, Karlsson G, Ringner P, Sanner E, Schrewelius C. Clinical efficacy of budesonide in the treatment of eczematous external otitis. Eur Arch Otorhinolaryngol. 1991;248:246-9.

12. Emgard P, Hellstrom S. A group III steroid solution without antibiotic components: an effective cure for external otitis. J Laryngol Otol. 2005;119:342-7.

13. Canon SJ, Grunwaldt E. Treatment of otitis externa with a topical steroidantibiotic combination: a contolled clinical trial. Eye Ear Nose Throat Monthly 1967;46:1296-302.

14. Shrestha BL, Shrestha I, Amatya RC, Dhakal A. Effective treatment of acute otitis externa: a comparison of steroid antibiotic versus $10 \%$ ichthammol glycerine pack. Indian J Otolaryngol Head Neck Surg. 2010;62:350-3.

15. Hornigold R, Gillett D, Kiverniti E, Harries M. The management of otitis externa: a randomised controlled trial of a glycerol and icthammol ribbon gauze versus topical antibiotic and steroid drops. Eur Arch Otorhinolaryngol. 2008;265: 1199-203.

16. Masood A, Moumoulidis I, Ray S, Chawla O, Panesar J. A randomised controlled trial comparing Triadcortyl with $10 \%$ glycerine ichthammol in the initial treatment of severe acute otitis externa. Eur Arch Otorhinolaryngol 2008;265:881-5

17. Koch K. Managing otitis externa. S Afr Pharm J 2012;79:17-22.

18. Gray RF, Sharma A, Vowler SL. Relative humidity of the external auditory canal in normal and abnormal ears, and its pathogenic effect. Clin Otolaryngol 2005;30:105-11.

19. Ruckenstein MJ. Infections of the external ear. In: Cummings $\mathrm{CW}$ et al (eds) Otolaryngology head and neck surgery, $4^{\text {th }}$ edn, vol 3. Elsevier Mosby, Philadelphia, pp 2979-87.

20. Bhatta R, Pokharel R, Adhikari P, Neupane Y. A comparison of $10 \%$ ichthalmmol glycerine packs with steroidantibiotic pack for relieving pain in cases of acute otitis externa. J Inst Med 2009;31:7-10.

21. Neher A, Nagl M, Scholtz AW. Otitis externa: etiology, diagnostic and therapy. HNO. 2008;56:1067-79. 